\title{
Memória e topofilia no semi-árido baiano: imagens do cotidiano de velhos agricultores do sisal
}

\author{
ALESSANDRA ALEXANDRE FREIXO \\ ANA MARIA FREITAS TEIXEIRA
}

Resumo

O intuito deste artigo é apreender os sentidos produzidos por velhos agricultores do município de Valente (Bahia, Brasil) sobre seu lugar, tomados como ponto de partida para a compreensão de suas relações no ambiente. Para tanto, nos apoiamos em narrativas, bem como em registros fílmicos, adotados como matéria prima para a construção de uma memória sobre o lugar, inextricavelmente articulada às vivências cotidianas dos velhos e suas representações do passado, atuando como coadjuvante na interpretação de sua realidade.

Palavras-chave:

Registro fílmico, região sisaleira, memória coletiva 


\title{
Memory and topophilia in Bahia semi-arid: images of everyday life from old farmers of sisal
}

\author{
ALESSANDRA ALEXANDRE FREIXO \\ ANA MARIA FREITAS TEIXEIRA
}

\section{Abstract}

The purpose of this paper is to understand the meanings produced by elderly farmers in Valente (Bahia, Brazil) about their place, taken as a starting point for understanding their relationship to the environment. For this, we rely on stories as well as in filmic records, taken as raw material for the construction of a memory about the place, inextricably articulated to the daily experiences of the elder and his representations of the past, that serves as an adjunct in the interpretation of their reality. 


\section{Introdução}

O intuito desse artigo é apreender os sentidos produzidos por velhos agricultores de localidades rurais do município de Valente (Bahia) sobre o lugar onde vivem, sentidos estes tomados como ponto de partida para a compreensão das relações destes sujeitos em seu ambiente.

Para empreender tal análise, nos apoiamos tanto nas narrativas produzidas pelos velhos agricultores ao longo das entrevistas, como em fotografias e imagens videográficas produzidas ao longo desta pesquisa. Assim, tanto as narrativas quanto as imagens constituem a matéria prima para a construção de uma memória sobre o lugar, estando estas inextricavelmente articuladas na compreensão das vivências cotidianas dos velhos e de suas representações do passado, atuando como coadjuvantes e complementares na interpretação de uma dada realidade. Rumo à compreensão das memórias de velhos agricultores sobre seu lugar buscamos, neste artigo, a elaboração de um diálogo entre as narrativas dos velhos e os registros fotográficos e fílmicos, de modo a compor uma possível interpretação das relações dos velhos agricultores em seu ambiente.

Munidas de uma máquina fotográfica e uma filmadora digitais, além do tradicional gravador e do caderno de campo, buscamos privilegiar não apenas os significados expressos nas narrativas orais dos sujeitos, mas também apreender os sentidos que os velhos atribuem aos lugares em que tecem seu cotidiano. Neste sentido, para além do registro da fala, procedemos ao registro fotográfico e fílmico dos "lugares que falam" aos velhos, na tentativa de apreender os sentidos que eles conferem a esses lugares e o que lhes confere sua "topofilia" (TUAN, 1980), ou seja, o que faz desses lugares referências de vida para os velhos. 
Segundo Tuan, a topofilia, termo por ele forjado, é definida como os "laços afetivos dos seres humanos com o meio ambiente material" (p. 107), que podem envolver desde um componente estético, ou tátil, até sentimentos para com o lugar. A topofilia tende a ser mais intensa à medida que se relaciona a acontecimentos emocionalmente fortes ou tornase um símbolo, como com relação ao lar, a lembranças do passado, ou ainda referida ao lugar do "ganhar a vida" (TUAN, 1980, p. 107). É neste sentido que Tuan relaciona o apego à terra por um agricultor, fonte do sentimento topofílico e símbolo de pertencimento ao lugar:

A topofilia do agricultor está formada desta intimidade física, da dependência material e do fato de que a terra é um repositório de lembranças e mantém a esperança. A apreciação estética está presente, mas raramente é expressada. (TUAN, 1980, p. 111)

Esta compreensão da topofilia se aproxima, em grande medida, ao que Brandão (1999) identifica como "o afeto da terra", referindo-se a uma possível "ética camponesa da natureza", a partir da qual agricultores e criadores de gado de um município da Serra da Mantiqueira, em São Paulo, relacionam-se com a natureza e com seu ambiente em suas vidas cotidianas. Nesta obra, Brandão, tal com Tuan, preocupa-se em compreender as percepções, valores e atitudes de seres humanos em seu ambiente e como estas percepções, valores e atitudes se conformam em suas relações com o outro - sejam os homens e mulheres do lugar, os outros seres humanos "de fora" (aqueles que chegam com o "progresso"), a terra, as plantas, ou os animais.

É este apego, este afeto, que consideramos ser fundamental no processo de pertencimento ao lugar. Vale ressaltar que este pertencimento afetivo não significa "isolamento" ou "fixação" ao lugar, mas acima de tudo, tomar o lugar como uma referência que, de algum modo, informa as vivências cotidianas das pessoas, mesmo que estas se desloquem a outros lugares.

Desse modo, apelar para a dimensão afetiva é sair em busca das "raízes" do lugar e perceber como as lembranças dos velhos sisaleiros produzem cotidianamente estas "raízes", é emaranhar-se nessas raízes para encontrar os elos de pertencimento desse grupo social. Enfim, buscar compreender essa "comunidade afetiva" (HALBWACHS, 2004) que permite que a memória coletiva se produza e reproduza socialmente e possibilite um enraizamento ao lugar. 
Nesse caminho de apreensão dos sentidos topofílicos conferidos aos lugares, todos os registros foram acompanhados do diálogo com os depoentes. Essa "conversa" que envolveu cada foto permitiu que os sujeitos da pesquisa indicassem objetos, espaços, situações e ângulos a serem registrados. Assim, tanto no momento da tomada das imagens, quanto no momento de sua apresentação aos depoentes, promovemos um diálogo entre as perspectivas das pesquisadoras e dos entrevistados.

Assim, os registros das imagens fotográficas e, principalmente, fílmicas, possibilitaram uma análise mais ampla das relações em que se inserem estes agricultores, por permitir uma ampliação do campo de observação e registro das pesquisadoras, uma vez que não apenas o dito (a fala), mas também o não-dito (os gestos, os movimentos e o espaços de vivência dos sujeitos) que compõem a relação entre entrevistados e entrevistadores passa a ser objeto de investigação no encontro etnográfico (PEIXOTO, 200o).

É neste sentido que apresentamos aqui algumas co-produções imagéticas (fílmico-fotográficas) de dois velhos agricultores de Valente, elaboradas ao longo de nosso encontro etnográfico com estes sujeitos: a produção de Dona Su, reconhecida no lugar por suas habilidades na confecção de panelas de barro; e a produção de Seu Joaquim, que nos convidou a um "passeio" à sua propriedade, durante o qual tivemos oportunidade de registrar parte da diversidade de plantas que circulam no cotidiano vivido pelo velho agricultor, bem como os saberes constituídos em torno destas plantas (principalmente as medicinais) ao longo de anos de sua convivência com a caatinga.

\section{Dona Su: produzindo panelas e memórias}

Dona Marcimina da Silva (81 anos), conhecida por “Dona Su”, é uma das mais antigas moradoras da localidade Cipó de Leite. Esta localidade destaca-se na região pelos fortes elos de parentesco que os moradores estabelecem entre si e com Seu José Romão da Silva, o patriarca da família, gerando em torno dessa figura uma espécie de "mito de ancestralidade", no qual se observa a figura de um "herói desbravador" ou um "pai fundador" - Romão, reconhecido pelas pessoas do lugar por seus feitos na "fundação" desta localidade. Todas as pessoas do lugar tendem, então, a estabelecer e/ou acentuar um vínculo de parentesco com Romão e seus descendentes, mesmo que na condição de "parente" ou "primo" distante, ou ainda por meio do casamento entre parentes, o que reforça o pertencimento 
de todos que aí residem a essa árvore genealógica que remete a José Romão da Silva.

Dona $\mathrm{Su}$, dado seu parentesco próximo a este "herói fundador", seu pai, passou a ser reconhecida como uma legítima contadora da "história da comunidade Cipó", apesar de ela mesma assumir-se como uma pessoa que nada sabe, ou nada tem a contar, exceto pelas habilidades na confecção de panelas de barro. Em circunstância de suas vivências em torno da produção artesanal de panelas, sua narrativa ganha relevância justamente pela descrição detalhada que faz de todo processo de transformação do barro em diversos utensílios domésticos, desde a extração do barro até a elaboração final desses objetos.

O cotidiano do trabalho ao longo da juventude é descrito por Dona Su pelos momentos alternados entre o trabalho na roça e a produção de panelas de barro, processo que, segundo a velha agricultora, leva cerca de uma semana. Enquanto relata este processo, Dona Su nos convida a "dar um passeio" em seu quintal, de modo a procurar os utensílios outrora usados na produção de panelas, que há muito deixou de fabricar. Em seu relato, Dona Su faz uma clara distinção entre os jovens, do "tempo de hoje", e seus utensílios domésticos, e "seu tempo de moça", praguejando com relação à utilização de panelas de alumínio e fogões a gás que, segundo ela, prejudicam a qualidade e o sabor dos alimentos. Lamenta ainda que suas filhas e netas não saibam mais fazer panelas, que se tornaram símbolo de um outro tempo: o tempo dos velhos.

Dona Su (S.) assim resume o processo de produção das panelas, enquanto reúne os utensílios e materiais necessários para esta tarefa, que se encontravam espalhados pelo quintal:

(S.) A gente arranca o barro preto, o barro é preto! A gente arranca, "pisa"1 ele todinho, cata as pedras, é difícil! Tem umas pedras dentro, é difícil!

Aqui a mistura da telha, olha aqui! É, aqui que quebra todinha [a telha]. Pisa [a telha] no pilão! Pra [depois] misturar com o barro. O barro, coloca hoje e deixa de molho, para amanhã amanhecer mole. Amanhã, coloca a telha.

Olha, quando a gente arranca [o barro], que está assim [molhado], a gente não cata a pedra, mas é bom que já está molhado. Está bem molhado hoje...

Olha os cacos do capuco ${ }^{2}$ ! Aqui é pra alisar [a panela] todinha, por dentro. Eu vou guardar!

Aqui são os cacos de cuia ${ }^{3}$. Que é pra poder fazer a panela, 
pra ficar toda lisinha por dentro.

E aqui, os capucos pra passar...

A gente faz hoje, amanhã raspa [com o caco de cuia] e passa o capuco, pra ela ficar toda boa.

Aí eu volto e aliso com mucunã ${ }^{4}$. Sabe o que é mucunã? Eu andava com um no bolso... Eu usava um no bolso.

$\left(\mathrm{P}^{5}\right)$ Isso é toar?

(S.) Toar!

(P.) Toar pra ficar mais fina a ponta [da panela].

(S.) Tem umas pedrinhas pra gente passar assim... [me mostra como afinar a borda da panela]

(P.) Essa cera vermelha você passa na panela?

(S.) Aqui, vai soltando as pedras tudo.

(P.) Não serve se passar uma peneira não, né?

(S.) Não, peneira não presta não, não gosto.

Dona Su, agachada sobre os calcanhares (Figura 1), começa seu trabalho de transformação do barro, "pisando" o barro e separando todas as pedras que, segundo ela, prejudicam a confecção das panelas. Permanecendo nesta posição por horas, Dona Su não demonstra cansaço, nos explicando o modo certo de moer o barro, tarefa exclusivamente manual. Nem sequer peneiras devem ser usadas para separar as pedras, já que o barro deve ser mantido umedecido durante todo processo de produção da panela. Ao longo das filmagens do vídeo, em virtude da protagonista passar horas numa mesma posição, acocorada, optamos pela alternância entre um ângulo plano (horizontal) e um ângulo alto (de cima para baixo).

Cientes dos riscos de tomadas em ângulo alto, esta escolha se deu principalmente pela dificuldade das pesquisadoras em manter uma posição horizontal em relação à protagonista, já que não dispúnhamos de equipamentos que permitissem o ajuste do ângulo de filmagem, bem como pelo próprio amadorismo com que as imagens foram registradas: tanto nós pesquisadoras quanto uma pessoa do lugar, que nos acompanhou no processo das entrevistas, foram os responsáveis pela produção destas imagens, o que gerou de certo modo uma despreocupação com relação a estes ângulos. Por outro lado, no momento de edição das filmagens, optamos por manter várias cenas em ângulo alto, na tentativa de aproximar a protagonista de seu objeto de trabalho: o barro a se transformar, por sua arte de confeccionar panelas. 
qualidade desejada. O lugar de onde retira o barro está a cerca de $2 \mathrm{~km}$ de sua residência, distância essa que percorre a pé, e nos pede para acompanhá-la. Ao chegar ao lugar, Dona Su nos mostra um grande buraco, em meio à roça, aberto por dezenas de vezes em que extraiu barro para suas "panelinhas", como diz, em tom carinhoso, subjetivando seu trabalho. Trata-se da propriedade de um sobrinho, à qual Dona Su, por seus laços familiares, tem livre acesso, o que possibilita a ela, mesmo que esporadicamente, ter acesso à matéria-prima de sua produção.

Conforme nos conta a senhora, em sua localidade, as mulheres, além do trabalho na roça, contribuíam - e contribuem até os dias atuais - na renda familiar produzindo também, artesanalmente, esteiras e chapéus de palha, além de panelas de barro. Aqui, o aprender com os mais velhos aparece como a base do processo de socialização, em que a oralidade e a convivência nos diferentes espaços da vida cotidiana (a roça, a cozinha, fabricação de utensílios, etc.) tem papel central. Aprendia-se fazendo junto com o outro e, nessa relação, os saberes do lugar eram transmitidos aos mais jovens. Esses saberes do lugar, as cantigas de batalhão, as rezas, as danças, o manejo da terra parecem correr o risco de se transformar numa referência distante na memória.

Estes saberes inscritos no cotidiano do lugar, conforme nos sugere Escobar (2005), conformam-se a partir de "práticas passadas e em mudança” (p. 5), que pouco dependem de um sistema formal e descontextualizado de conhecimentos, característico do modelo eurocêntrico de saber. Estes ditos saberes práticos, advindos da experiência cotidiana, em decorrência da dominação e da colonialidade do saber formal, traduzem-se para os velhos como uma forma de não-saber, retratando uma distinção comum no lugar entre os "sabidos" (detentores do saber formal, mediado pela educação escolar e que reflete em grande medida ideais citadinos) e o "povo", aqueles que não sabem e, em geral, vivem na roça, categoria na qual os velhos se incluem.

Em decorrência dessa colonialidade do saber (ESCOBAR, 2005), que se impõe no lugar, os saberes práticos, ou ainda, os "saberes criativos" ou o "savoir-faire", característicos do trabalho feminino, como sugere Porto-Gonçalves (2006), vem sendo progressivamente substituídos pelo chamado "know-how", ou propriamente o "saber produtivo", repetitivo, representado pela presença das panelas de alumínio, que tomam o espaço daquelas de barro na preparação cotidiana dos alimentos. Desse modo, a produção de panelas de barro constitui-se claramente num sa- 


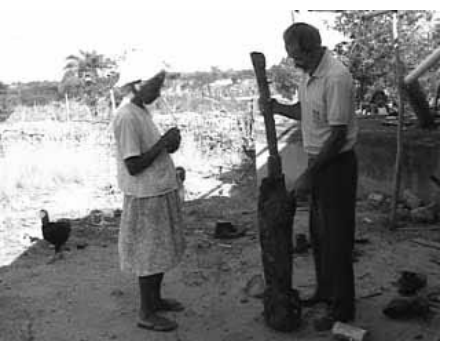

Figura 3

Cena do Vídeo "Saberes do cotidiano”: Dona Su e um amigo da família, encenando a moagem da telha. ber prático, criativo, que marca uma relação própria das mulheres do lugar com a natureza. Nesse processo de apropriação técnica da natureza, não apenas o barro deve ser cuidadosamente escolhido, bem como diversos materiais (a telha triturada e misturada ao barro, o "capuco" de milho, o "mucunã") encontrados no lugar são utilizados criativamente nessa produção.

Também advindo deste saber criativo é o pilão artesanal, adaptado de um tronco de baraúna, árvore nativa da caatinga, reconhecida no lugar por sua madeira de ótima qualidade. Assim, um pedaço de tronco se transforma em pilão, indispensável no momento de "pisar os cacos de telha", ou seja, de moer pedaços de telha para, com este pó de telha moída, dar liga ao barro, etapa fundamental na produção da panela. Ao nos relatar esta etapa de produção das panelas, Dona Su sai em busca do pilão e outros utensílios espalhados em seu quintal, para iniciar a encenação, auxiliada por um amigo, que "pisa o barro", recriando e relembrando junto com a artesã os momentos em que ela fazia panelas em grande quantidade para vender na feira (Figura 3).

(L. ${ }^{6}$ ) Tronco de baraúna. Pesado mais que o trem!

(P.) É tronco de baraúna, é?

(S.) Se fosse todo assim, era ligeiro!

A panela de barro, produto de um "savoir-faire", saber criativo da mulher, pouco valorizado no lugar atualmente, disputa espaço com as panelas de alumínio, produtos do "know-how" produtivo, que marcam a instituição de uma nova ordem distante (LEFEBVRE, 1991), na qual o alumínio se impõe no lugar. Dona Su ressente a preferência pelas panelas de alumínio, e o desconhecimento da maior parte das pessoas do lugar, inclusive suas filhas e netas, que em geral não reconhecem sua produção como um saber historicamente constituído.

As minhas meninas cansaram de fazer. [Mas hoje] quem é que vai aprender a fazer uma panela? Um trabalho difícil como é, Deus me livre! [...] quando eu morrer, não tem quem sabe fazer uma panela, pode? [...] Quando as filhas não querem, que são mais velhas, pior as netas! Tinha que continuar, elas [as filhas] mesmo faziam. Faziam aquelas tortas e ajeitava. (Dona $\mathrm{Su}, 81$ anos)

Assim como Dona Su guarda os "saberes criativos" que lhe permite transformar o barro em panelas, outro velho agricultor de Valente, Seu Joaquim, nos revelou uma outra ordem de saberes construídos na vida cotidiana junto à caatinga. 


\section{Seu Joaquim Costa e seus saberes que curam.}

Seu Joaquim (78 anos) mora em uma localidade rural chamada Varginha de Dentro, no município de Valente. Seu Joaquim, indicado por seus parentes e outras pessoas do lugar como um "bom contador de histórias", goza de grande autoridade como "guardião da memória" do lugar.

No momento da entrevista e da gravação das imagens para o vídeo estava também presente um amigo e vizinho da família, que fez importantes intervenções e que, de algum modo, assumiu o papel de entrevistador, o que nos permitiu outro olhar em torno das histórias contadas, enriquecido com a experiência de uma pessoa do lugar. Nesse caso particular, nossas intervenções foram mais no sentido de obter esclarecimentos em torno das histórias contadas, do que orientar o curso da entrevista.

E assim se inicia a história contada por Seu Joaquim:

No mundo de hoje, não está muito fácil, não. Porque, devido à violência, devido ao povo não respeitar mais ninguém. Eu estou pensando o que é isso que está faltando, caso de a gente chegar perto e aconselhar. Que outra coisa não tenho, a não ser conselho. Porque, eu acho que tem que ser assim. E minha história, pra contar, é contar o começo da minha vida! Não é outra coisa, que eu, outra coisa, não sei lhe contar. Que infelizmente, eu só conheço isso aqui, Salvador, porque eu tenho filho, que mora lá, e mais nada! [...] A senhora é católica?

É nesse viés do conselho que a entrevista segue seu rumo, ao longo da qual Seu Joaquim conta sobre sua história e aconselha os seus interlocutores a seguir o "caminho do bem", representado pela reza e pelo trabalho, ofícios que aprendeu com o pai. Assim, somada à lógica do trabalho, a reza, a religião católica, oferece uma chave de leitura da realidade e do passado, norteando, em grande medida, os relatos do agricultor. Esse aspecto se reflete frente a questão que nos foi colocada: “a senhora é católica?", como uma espécie de passaporte de entrada em seu mundo de histórias.

Este velho camponês, um "mestre da arte de narrar", nos diria Walter Benjamin (1987, p. 199), parte de seu universo essencialmente católico, que se constitui como chave de sua experiência vivida, para não apenas "contar histórias", mas, principalmente, aconselhar o ouvinte, tomando como base sua vivência no lugar (a "minha história"), coisas que para ele 
taurando um novo espaço-tempo. Entretanto, a inserção da cultura do sisal não significa uma ruptura com as atividades anteriormente desenvolvidas na propriedade: atualmente, Seu Joaquim ainda mantém algumas cabeças de gado e alguns burros, como herança dos tempos de seu pai.

Esta herança imaterial (LEVI, 200o) é tamanha que a narrativa de Seu Joaquim destaca-se das demais pela riqueza de detalhes em torno da atividade dos tropeiros: os trajetos realizados pelas tropas, os suprimentos que traziam de lugares distantes e, ainda, a presença de "cangaceiros" e "revoltosos"7, que constituíam uma constante ameaça aos tropeiros. É também distintivo o tratamento que Seu Joaquim confere a seus burros, mesmo tratamento conferido por seu pai: os burros, para além de constituírem um meio de transporte nas tropas, estavam presentes em muitos momentos de seu cotidiano, participando de rituais como casamentos - Seu Joaquim conta de uma "burra" em especial, que levava as noivas à igreja. Além disso, por maior que fosse a tropa, todos os animais tinham um nome, o que se traduz numa relação diferenciada entre os homens e mulheres e seus animais: atribuir um nome a um animal confere uma forte aproximação entre o animal e seu dono, enfim, confere ao animal uma "personalidade", numa relação que está para além de sua utilização como transporte (THOMAS, 1988, SAHLINS, 2003).

A forte relação que Seu Joaquim mantém com seu animais é tamanha que, em seu convite para conhecermos sua propriedade, após prolongada entrevista, o agricultor prepara-se para o passeio, colocando sua espora no pé e segue para sua montaria. A espora, "caixa de marcha do jumento" (Figura 5), na fala de um amigo que nos acompanhava, abre o caminho para nosso roteiro improvisado, rumo à roça, à procura dos saberes inscritos no "pedaço" de caatinga, que o narrador nos apresenta, sempre ao lombo de um jumento (Figura 6).

(L.) Essa aí é a caixa de marcha do jumento. [...] Na hora que o jumento está devagar, é só reduzir a engrenagem [...].

Assim, acompanhamos todo o percurso desse narradorvaqueiro desde o momento da preparação da indumentária de montaria (a espora), até chegarmos ao ponto culminante do vídeo-documentário - a cajazeira, importante elo identitário do velho agricultor ao seu lugar. Em todo este percurso, da casa à cajazeira no interior da caatinga, seguimos a pé, ao lado de Seu Joaquim, sempre montado no jumento, o que nos

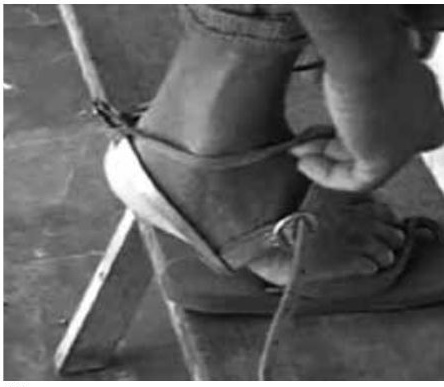

Figura 5

Cena do Vídeo "Saberes que curam": Seu Joaquim preparando a "caixa de marcha do jumento", para o passeio rumo à caatinga.

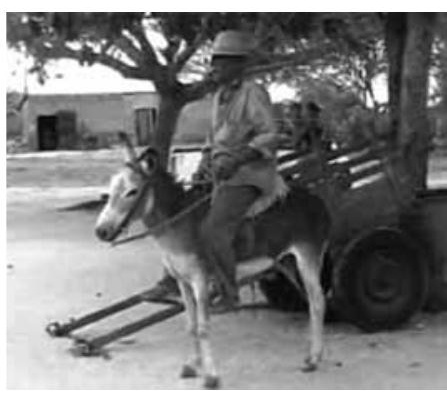

Figura 6

Cena do Vídeo "Saberes que curam": Seu Joaquim ao lombo do jumento. 
fez privilegiar tomadas em ângulo baixo (de baixo para cima, já que estávamos, em geral, em posição inferior em relação ao protagonista), o que confere ao narrador uma posição de destaque e mesmo de altivez. Este tipo de tomada findou por ser privilegiada no momento da edição do vídeo, o que pode induzir ao expectador a uma valorização deste narrador, bem como dos saberes de seu cotidiano.

Destaca-se ainda no vídeo-documentário, bem como ao longo da entrevista, o apreço especial que o narrador possui por uma cajazeira, a qual identifica como uma representante da memória do seu pai.

(J.) Tinha uma cajaeira, o vento derrubou ela, ela ficou deitada no chão, ainda hoje está lá, eu não mexo! Um dia desse eu quase briguei. [...] o cara que foi tirar um teiú, foi lá e cortou de machado a cajaeira, e ela acabou de cair uma banda. E depois eu soube quem foi, eu fui lá e falei com o cara! "Mais nunca! Você deixa o tempo levar. Se ela morrer, morre com o tempo." Não gosto de destruir uma coisa que eu preciso. É o mal do povo, é esse! Porque, se você precisa de uma coisa, destruir, acaba.

(A.) E por que o senhor precisa da cajaeira?

(J.) Por que eu preciso? Uma lembrança que eu tenho do meu pai. Porque, o meu pai, quase todo o dia, meio-dia, ele sentava na própria raiz da cajazeira e ele encostava. Naquele pau que era deitado. E aí, eu fiquei respeitando aquilo, e ainda hoje respeito, que estou com vida, né? E eu tenho um filho aí, se eu pedir a ele, ninguém mexe!

Aqui a árvore assume um importante papel na memória, como uma espécie de "sacerdotisa e guardiã da história imemorial" (SCHAMA, 1995) da família, como um tributo, uma prova indiscutível de que os laços de família nunca morrem mesmo quando a vida se acaba e o tempo se arrasta. A árvore, assim personificada como lembrança do pai, preenche a caatinga de significados míticos, para além dos possíveis usos materiais, como obtenção de lenha ou ainda como terra cultivável. A caatinga - agora reverenciada como altar - e a cajazeira - como "sacerdotisa" da memória familiar - devem ser preservadas, aos olhos deste agricultor. É este olhar do agricultor que buscamos transpor, pelas lentes das câmeras, aos expectadores, na tentativa de traduzir em elementos audiovisuais, a imagem mítica de uma árvore que gera frutos de memória, a alimentar as lembranças de todo um grupo familiar e que, aos olhos do agricultor, deve ser preservado no 
lugar. Assim buscamos traduzir a imagem expressa na cena a seguir (Figura 7).

(J.) O caso dessa cajaeira aqui é o seguinte. Ele disse que vai desmatar. Mas ele não é doido para bulir aqui. Deixa aí! O dia que eu morrer, eles façam o que quiser.

A cajazeira e seus troncos retorcidos são, ao mesmo tempo, monumento em memória aos antepassados de Seu Joaquim e espelho de seu compromisso em manter a mata nativa como documento da sabedoria simples de quem entende que todos os elementos da natureza estão profundamente interligados.

A partir do vídeo, pudemos nos aproximar do cotidiano vivido pelo velho agricultor, que logo nos apresenta o remanescente de caatinga que mantém em sua propriedade. A caatinga que marca a região sisaleira da Bahia é rica em plantas que curam e esse conhecimento faz parte da vida dos velhos, uma herança que perpassa gerações, um "patrimônio" construído ao longo do tempo como uma "ciência” própria aos homens e mulheres da Terra do Sisal.

Juá, Caçutinga, Pinhão, Imbira, Mocó são algumas das plantas da caatinga apresentadas pelo agricultor, que silenciosamente guardam as propriedades de curar o corpo e, às vezes, até mesmo a alma. Seu Joaquim em meio a suas lembranças nos faz pensar a ligação entre o homem e a terra.

Tivemos a oportunidade ainda de registrar outros saberes inscritos no lugar, revividos na memória de nosso "conselheiro”. Dentre estes, destaca-se a fé na oração, para enfrentar os desafios de se embrenhar nas matas e sobreviver, que se expressa no ritual da Correia Curada, usada para salvar das picadas de cobra. Seu Joaquim conserva sua correia por gerações. Trata-se de uma correia especial, fabricada num ritual particular, quando vários nós foram feitos no couro, enquanto seu compadre fazia uma oração benzendo e pedindo ao sagrado a proteção. Os nós "prendem" a oração na correia e aquele que a utiliza, amarrada próximo à picada de cobras, tem a chance de se salvar (Figura 8).

(P.) O que é a correia curada?

(J.) A correia curada é benzida. Os velhos antigos benziam. Quando a cobra mordia, você pegava e amarrava ela no lugar. Eu já amarrei em José [filho].

(L.) Que aqui dentro tem uma oração que expulsa o efeito

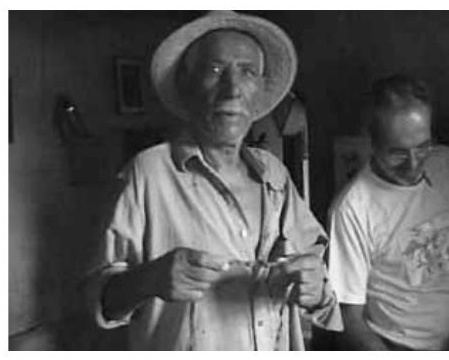

Figura 8

Cena do vídeo "Saberes que curam": narrativa sobre o ritual da correia curada. 
do veneno da cobra. Aí, não precisa tomar nada? Outro medicamento?

(J.) O José não tomou nada, ele tomou cachaça. Isso é coisa dos antiguíssimos!

\section{Conclusão}

Nesse percurso entre produção fotográfica e diálogo com os informantes dessa pesquisa, evidenciou-se claramente o papel da imagem (fotográficas ou fílmicas) como meio não apenas de "materializar" memórias, mas também um importante elemento de comunicação e, sobretudo, de conhecimento de si e do outro. Nesse processo de conhecimento e reconhecimento de si e do outro, nos inserimos como "estranhas", e com o apoio de uma máquina fotográfica e de uma filmadora, não apenas co-produzimos imagens, mas também compartilhamos lembranças, e participamos da produção de outras memórias, já que cada imagem produzida apresenta-se prenhe de recordações.

Na medida em que os velhos tiveram acesso às imagens fotografadas ou filmadas imediatamente após sua tomada mediante a utilização de equipamentos digitais, estes tornaram-se co-participes na construção desse momento, por vezes indicando ângulos e enquadramentos e opinando sobre cada fotografia ou tomada fílmica produzida.

Em que pesem os distintos olhares sobre as imagens ora apresentadas, foi possível perceber que elas, se analisadas como elementos vivos e em construção, não como dados imutáveis, podem trazer à tona narrativas que não foram reveladas pelas entrevistas. Assim, o recurso às imagens fotográficas e videográficas, entretecidas às memórias relatadas nas entrevistas, desempenharam papel fundamental na compreensão das relações de sociabilidade inscritas no lugar.

Entretanto, tal como Darbon (2005), consideramos que a imagem não deve ser tomada como portadora de um sentido em si, de uma intencionalidade "inata", estando de alguma forma subordinada à narrativa, uma vez que quem confere sentidos à imagem são as pessoas que as produzem, nos contextos e nos lugares em que são produzidas.

Por outro lado, as pessoas não se esgotam em suas narrativas, não são apenas seres pensantes, capazes de expressarse exclusivamente pela narrativa oral. Há algo que a narrativa não é capaz de revelar, algo que as pessoas efetivamente sentem que é impossível de ser expresso em palavras. Neste 
sentido, a imagem pode contribuir para além da narrativa, expressando mais concretamente os sentimentos topofílicos (TUAN, 1980) dos velhos agricultores em relação aos lugares considerados memoráveis, como a casa, a roça e as plantas que fazem parte de suas vivências cotidianas.

Junto com os velhos, descortina-se a matéria-prima de que são forjadas suas memórias: o trabalho com a terra, a família, a religiosidade e a sabedoria que resiste à força e velocidade do tempo. Estes são alguns dos aspectos que buscamos investigar. O desafio enfrentado esteve, então, em buscar caminhos para articular narrativas e imagens sobre um modo de vida e sobre diferentes histórias de velhos e velhas, que se entrecruzam nas terras do sisal. Os relatos e imagens produzidas por estes velhos se constituem como importante elemento de reflexão sobre as transformações da paisagem do lugar e, conseqüentemente, uma importante contribuição para a reconstrução da memória de diferentes comunidades que se estabeleceram na região.

Neste sentido, o recurso à imagem como instrumento de pesquisa revelou-se potencialmente profícuo, constituindose num importante momento de observação e questionamento sobre o cotidiano vivido pelos velhos, bem como sobre suas redes de sociabilidade, principalmente quando em articulação com a memória e narrativa desses sujeitos. Neste contexto, a utilização da imagem fotográfica possibilitou uma maior visibilidade desses narradores e de sua "arte de dizer" (DEVOS, 2005). O narrador assume assim, nas palavras de Devos (2005), o status de "produtor de imagens", dando forma às estórias/histórias narradas. Neste sentido, a fotografia constituiu-se aqui num importante elemento de interpretação das transformações ocorridas no lugar onde convivem estes velhos narradores.

\section{Referências}

BENJAMIN, Walter. Magia e técnica, arte e política: ensaios sobre literatura e história da cultura. 3. ed. São Paulo: Brasiliense, 1987.

BRANDÃO, Carlos. R. O afeto da terra. Campinas: UNICAMP, 1999.

DARBON, Sébastien. O etnólogo e suas imagens. In: SAMAIN, Etienne (Org.). O fotográfico. 2. ed. São Paulo: Hucitec/Senac, 2005.

DEVOS, Rafael V. "Pra lá pra aquele lado lá tudo é assombra- 
do": memória, narrativa , espaço fantástico e a questão ambiental. Iluminuras, n. 59, 2005, p. 1-32.

ESCOBAR, Arturo. O lugar da natureza e a natureza do lugar: globalização ou pós-desenvolvimento? In: LANDER, Edgardo (Org.) A colonialidade do saber: eurocentrismo e ciências sociais. Buenos Aires: CLACSO, 2005. Disponível em: http://bibliotecavirtual.clacso.org.ar/ar/libros/lander/pt/Escobar.rtf. Acesso em: 21. mai. 2009.

HALBWACHS, Maurice. La memoria colectiva. Barcelona: Univ. Zaragoza, 2004.

LEFEBVRE, Henri. The production of space. Oxford: Blackwell Publishing Ltd, 1991.

LEVI, Giovanni. A herança imaterial. Rio de Janeiro: Civilização Brasileira, 2000.

PEIXOTO, Clarice E. Envelhecimento e imagem: as fronteiras entre Paris e Rio de Janeiro. São Paulo: Annablume, 2000.

PORTO-GONÇALVES, Carlos Walter. A globalização da natureza e a natureza da globalização. Rio de Janeiro: Civilização Brasileira, 2006.

SAHLINS, Marshall D. Cultura e razão prática. Rio de Janeiro: Jorge Zahar, 2003.

SCHAMA, Simon. Paisagem e memória. São Paulo: Companhia das Letras, 1995.

RICOEUR, Paul. A memória, a história, o esquecimento. Campinas: UNICAMP, 2007.

TERRA de Memórias, os velhos do sisal. Produção de Alessandra A. Freixo e Ana Maria F. Teixeira. Feira de Santana: UEFS, 2007. Volume 1. Saberes do cotidiano. 1 DVD (21 min), som., color.

TERRA de Memórias, os velhos do sisal. Produção de Alessandra A. Freixo e Ana Maria F. Teixeira. Feira de Santana: UEFS, 2007. Volume 2. Saberes que curam. 1 DVD (27 min), som., color.

THOMAS, Keith. O homem e o mundo natural: mudanças de atitude em relação às plantas e aos animais. 1500-180o. São Paulo: Companhia das Letras, 1988.

TUAN, Yi-Fu. Topofilia: um estudo da percepção, atitudes e valores do meio ambiente. São Paulo: DIFEL, 1980.

\footnotetext{
NOTAS

1. Referência ao processo de moagem do barro.

2. Sabugo de milho.

3. Pedaços de panelas quebradas.
} 
4. Semente também conhecida como "olho de boi".

5. Pesquisadora.

6. Liderança comunitária local, que nos acompanhou no processo de produção fílmica.

7. Seu Joaquim faz uma distinção entre os "cangaceiros", os homens liderados por Lampião e Corisco, e os "revoltosos", que entravam nas fazendas e sequiestravam os burros nos pastos. Estes últimos provavelmente estivessem ligados à Coluna Prestes, dada a proximidade do relato aos acontecimentos que sucederam no lugar, em meados da década de 1920.

Recebido em: 06/06/11

Aceito em: 11/10/11

\section{ALESSANDRA ALEXANDRE FREIXO aafreixo@hotmail.com}

Licenciada em Biologia, pela Universidade Federal do Rio de Janeiro (UFRJ) e mestre em Agronomia pela Universidade Federal Rural do Rio de Janeiro (UFRRJ) em Doutora em Ciências Sociais pela UFRRJ. Em 2001 ingressou no Departamento de Educação da Universidade Estadual de Feira de Santana (UEFS), tendo atuado desde então em estudos que envolvem as temáticas Meio Ambiente e Educação Ambiental. Em 2005, iniciou pesquisas sobre a memória de comunidades rurais no território sisal, que culminaram em sua tese de doutorado, concluída em 2010. Atualmente é Professora Adjunta da UEFS e Pesquisadora do Núcleo de Estudos e Pesquisa: Trabalho, Trajetórias e Educação (NETTE)/UEFS e da Equipe de Estudo e Educação Ambiental (EEA/UEFS), atuando em pesquisas sobre memória social, imagem e narrativa no mundo rural, tendo como principal campo de estudo o Território do Sisal.

\section{ANA MARIA FREITAS TEIXEIRA}

Graduada em Sociologia pela Universidade Federal da Bahia (UFBA), mestre em História Social pela USP, doutora em Ciências da Educação pela Universidade Paris 8. Atualmente é Professora Adjunta do Departamento de Educação da Universidade Federal de Sergipe (UFS) vinculada ao Núcleo de Pós-Graduação em Educação (NPGED) e ao Núcleo de Pós-Graduação em Ensino de Ciências e Matemática (NPGECIMA). Pesquisadora do Grupo Educação e Contemporaneidade (EDUCON)/UFS, atuando, sobretudo, nas seguintes linhas de pesquisa: trabalho e educação, sociedade, cultura e juventudes, relação com o saber, memória, representações e mundo rural. 